\title{
Literacia para as mídias: diálogos pedagógicos e sociais ${ }^{1}$
}

Ricardo Cocco ${ }^{2}$

Flávia Eloisa Caimi ${ }^{3}$

Luis Bonixe ${ }^{4}$

\begin{abstract}
Resumo
O texto trata do conceito de literacia, complexo processo educativo que se ocupa com o alargamento das capacidades para entender, interpretar e relacionar o conteúdo que o sujeito tem ao seu dispor com as práticas sociais diversas, ampliando suas possibilidades de atuação ativa, autônoma e crítica. Falamos em literacias ou multiliteracias. Dada a complexidade da sociedade contemporânea e a omnipresença das mídias, o presente estudo teórico de caráter bibliográfico aponta a necessidade da promoção de literacias que permitam ao sujeito estabelecer uma relação informada, crítica e responsável para e com elas. O cenário europeu e em especial o de Portugal são os aportes quando intencionamos compreender o que se pretende significar e promover ao adentrar no campo da Literacia para as mídias.
\end{abstract}

Palavras-chave: Processos Educativos; Literacia; Mídias.

\section{Media literacy: pedagogical and social dialogues}

\section{Abstract}

This text discusses the concept of literacy, that is a complex educational process which deals with the enlargement of the capacities to understand, interpret and relate the content that the person has at its disposal with diverse social practices, expanding possibilities of active, autonomous and critical action. We are talking about literacies or multiliteracies. Considering the complexity of contemporary society and the omnipresence of the media, this theoretical study of bibliographic character indentifies the need to promote literacies that enable the person to establish an informed relationship, critical and responsible to and with them. The European scene and especially the Portugal one are the contributions when we intend to understand what we intend to mean and promote when entering the field of Literacy for the media.

Keywords: Educational Processes, Literacy, Media.

\section{Introdução}

É notório o fato de que vivemos em um cenário socio-político em que o acesso, produção e a circulação de informações têm alcançado uma dimensão incomensurável e, junto com elas, a desinformação ou as chamadas fake news, que igualmente têm se disseminado largamente. É

\footnotetext{
${ }^{1}$ Artigo originário de pesquisa apoiada pela CAPES através do Programa de Doutorado Sanduíche no Exterior (PDSE-CAPES).

${ }^{2}$ Universidade Federal de Santa Maria Campus Frederico Westphalen (UFSM-FW) - RS, ricardo.cocco@ufsm.br

${ }^{3}$ Universidade de Passo Fundo (UPF) - RS, caimi.flavia@gmail.com

${ }^{4}$ Escola Superior de Educação e Ciências Sociais do Instituto Politécnico de Portalegre - Portugal, luis.bonixe@gmail.com
} 
bem verdade que este cenário não é novo, o inédito é a aparição de instrumentos, redes e mídias que, quando mobilizados, são capazes de reproduzí-las e disseminá-las com amplitude e velocidade surpreendente.

À medida que o conhecimento e a informação se encontram na base estrutural da sociedade contemporânea, as capacidades de produção e interpretação destas informações e conhecimentos, nos seus diversos aportes, plataformas e contextos, assumem um caráter decisivo.

É este cenário que nos servirá de horizonte para os diálogos que serão propostos neste artigo. Em face ao modo como os sujeitos acessam as informações, como as interpretam e depois como produzem seus discursos e conteúdos a partir delas usando as tecnologias de comunicação e informação disponíveis, o artigo debaterá acerca das possibilidades de habitar de forma crítica, criativa e responsável em tal ecossistema informativo e midiático.

Para isso acionaremos o conceito de literacia, compreendida e, dessa forma descrita na primeira parte do artigo, como um processo de aquisição de capacidades de reflexão e espírito crítico por parte do sujeito que o torna capaz de compreender e/ou analisar as informações, bem como avaliar os processos de criação e produção de conteúdos.

Em seguida o artigo problematiza a perspectiva da Literacia para as Mídias como valor fundamental para a comunicação e promoção da cidadania colocando a tônica não tanto nas mídias ou nas tecnologias, mas nas possibilidades de qualificação dos processos comunicativos mediados pelas tecnologias da comunicação e da informação e na aquisição de capacidades que permitam aos sujeitos estabelecerem uma relação informada, crítica e responsável para com as mídias. Subjaz a esta perspectiva uma ideia comum: "a importância de um processo de aprendizagem e de capacitação dos cidadãos frente às mídias, cujo objetivo último é o exercício autônomo de competências e capacidades face aos meios de comunicação, tanto os clássicos como os novos" (PINTO, 2011, p.24). O cenário europeu e em especial o de Portugal são os aportes quando intencionamos compreender o que se pretende significar e promover ao adentrarmos no campo da Literacia para as Mídias.

Por fim, faremos alguns apontamentos provocativos para a urgência da promoção de Literacia para as Mídias em contextos escolares como lócus privilegiado e apontado como central para o desenvolvimento de tais competências. Processos formativos que não se resumem à 
utilização técnica dos meios de comunicação, mas que estão associados às capacidades de acesso, avaliação, uso ético e eficaz de dados e informações na medida em que apostam na capacitação das pessoas para fazerem escolhas de forma autônoma e produzir conteúdos de forma crítica e criativa utilizando as potencialidades oferecidas pelas mídias.

\section{Primeiras palavras: um proêmio aos conceitos}

O conceito de literacia tem sido utilizado desde a década de 1980, simultaneamente, em diversos países do mundo, devido às intensas e constantes transformações ocorridas nas sociedades atuais e as novas exigências em leitura de mundo e da palavra que estes cenários apresentam. A concepção alarga o conceito de alfabetização, sem o dispensar. Enquanto a alfabetização caracteriza, convencionalmente, o ato de ensinar e de aprender a leitura, a escrita e o cálculo, muito ligado aos graus de escolarização e à aquisição de conteúdos e informações, literacia indica a capacidade de traduzir, usar, processar e compreender as competências e as informações aprendidas e ensinadas. Para Benavente (1995, p.23) "na literacia não se trata de saber o que é que as pessoas aprenderam ou não, mas sim de saber o que é que, em situações da vida, as pessoas são capazes de usar. A literacia aparece, assim, definida como a capacidade de processamento da informação escrita na vida quotidiana". Nesta perspectiva, o conceito de literacia não se relaciona com algo que é estático, algo a ser apreendido, memorizado e repetido, mas com um processo que, de modo complexo, é individual e ao mesmo tempo coletivo face às constantes mudanças que se operam na sociedade. Está ligado à capacidade de fazer uso social da leitura, da escrita e do conhecimento, processar, sintetizar e saber avaliar uma dada informação em uma situação ou em situações do cotidiano.

Literacia caracteriza-se como um processo amplo e complexo que se ocupa com o alargamento das capacidades para entender, interpretar e relacionar o conteúdo que o sujeito tem ao seu dispor com as práticas sociais diversas, ampliando suas possibilidades de atuação ativa, autônoma e crítica. Não é um estado ou condição estática. Nesse sentido, pretende-se superar as caracterizações dicotômicas como as que colocam em oposição os alfabetizados e os analfabetos, visto que tais distinções são redutoras da diversidade de situações e condições sociais existentes. Ou seja, não se limita à propriedade de um determinado conhecimento, ou à 
capacidade de apropriar-se dele, e mesmo não se refere à aquisição de credenciais escolares, antes, entende-se, por literacia, a capacidade de processamento, manuseio e crítica, na vida diária, de informações de uso corrente contidas nos mais diversos materiais acessíveis ao sujeito. Passa-se a falar de um processo mais radical, permanente e contínuo de aprendizagem que não pode ser inferido tendo por base os graus de escolaridade exigidos formalmente.

Não se trata, no entanto, da utilização, em maior ou menor grau, de forma funcional, utilitária ou pragmática, dos saberes adquiridos, mas refere-se a uma condição duradoura, passível de ser mobilizada num conjunto alargado de situações. Ou seja, não tem a ver meramente com os processos de certificação ou escolarização. Considerando a complexidade da sociedade contemporânea e a evolução tecnológica a que estamos expostos, a literacia referese às competências relativas à continuação da aprendizagem ao longo da vida e ao exercício de uma cidadania participativa e consciente, histórica e culturalmente situadas. O conceito de literacia versa-se ao uso das competências e não a sua obtenção ou posse. Nesta perspectiva, não se refere a uma mera aquisição de competências num dado campo, mas sim ao estabelecimento de um conjunto de condições individual, institucional e social que dê suporte e impulsione um processo educativo contínuo e ativo. Literacia não se adquire de uma forma espontânea, mas pressupõe a criação de oportunidades plurais de interação e aprendizagem, envolvendo uma diversidade de materiais disponíveis, assegurando que estes, para além de significativos e relevantes, sejam acessíveis na multiplicidade de contextos em que eles interagem e se movimentam. De fato, a capacidade de compreender, refletir e usar a informação começa a ser entendida como fundamental, em contrapartida a sua ausência passa a ser uma preocupação social.

A literacia está intimamente ligada à educação e à cidadania. À primeira, pois, muito mais do que o acesso à informação e ao conhecimento, os processos educativos, sejam eles escolares ou não, formais ou informais, não podem prescindir de uma reflexão sobre as questões implicadas em seu fazer. Para Pinto (2002, p.8), há dois grandes objetivos aos quais a educação deve responder: "fornecer os mapas de um mundo complexo e perpetuamente agitado e a bússola que nos permita nele navegar". Para ele, os mapas dizem respeito ao universo de conhecimentos e de saberes na contemporaneidade cada vez mais vastos e a bússola faz alusão à necessidade de pontos de referência que não nos deixem submergir pelos fluxos de informação 
mais ou menos efêmeros que invadem os espaços públicos e privados.

Do mesmo modo, a literacia está umbilicalmente ligada à cidadania, visto a urgência de reflexão face aos desafios colocados pela sociedade da informação e da tecnologia, sem a qual novas formas de exclusão tendem a emergir e a se acentuar. Somente o exercício de uma cidadania esclarecida, informada e participativa é capaz de conduzir a transformações e melhorias nas sociedades democráticas. Trata-se de um valor inquestionável para as sociedades democráticas contemporâneas, o que implica não apenas a garantia da igualdade e dos direitos em termos civis formais, ou à identificação a um território geopolítico, mas está ligado à participação ativa, consciente e qualificada do sujeito nos espaços em que está inserido, sejam eles no micro ou macrocosmos. O exercício de uma cidadania consciente e ativa está condicionado à capacidade dos indivíduos em reconhecer, compreender e agir criticamente frente ao que está a sua volta. Não pode haver cidadania sem liberdade, sem sujeitos autônomos e sem que haja condições materiais, sociais e epistemológicas que a efetivem. Ser cidadão não é uma condição dada por ordem divina ou por um toque de mágica, mas é uma construção constante e que no cotidiano encontra terreno para sua edificação. Cidadania não se reduz ao sentimento de pertença a uma comunidade ou a um rol de direitos e deveres associados a esta pertença, mas deve-se afirmar como um conjunto de práticas e de competências individuais e coletivas do cidadão. Neste sentido, a literacia, enquanto conjunto de capacidades técnicas, críticas, sociais e criativas, multidimensionais, que são desenvolvidas ao longo da vida, mobilizadas como resposta às exigências cada vez mais complexas dos contextos, e que permitem ou contribuem para que o sujeito responda de forma consciente e informada às necessidades da vida em sociedade, constituem-se em elementos indissociáveis à construção da cidadania.

Falamos, então, não somente em literacia (no singular), mas em literacias ou multiliteracias, visto que o conceito se apresenta de maneira fortemente complexa e polifacetada. Ou seja, ao considerarmos as complexidades e as dinâmicas da sociedade atual e apelarmos para um movimento de reflexividade permanente e continuadamente direcionado à utilização consciente e crítica de recursos e disposições para a ação e que permitem ao sujeito aceder, avaliar e analisar criticamente as mensagens recebidas nestes diversos contextos podemos falar em literacias. Fala-se, desta maneira, em diversas aprendizagens nos âmbitos 
linguísticos, matemáticos, informacionais, tecnológicos, sociais, humanos etc. Em termos mais específicos, podemos encontrar estudos, por exemplo, sobre Literacia em Saúde, Literacia Digital, Literacia Linguística, Literacia da Informação, Literacia Científica ou Literacia para as Mídias (da qual trataremos a seguir). Ou mesmo associadas a diversos contextos pedagógicos como, por exemplo, Literacia e o ensino e compreensão da leitura, Literacia e práticas políticas, Literacia e a História, Literacia na aprendizagem de jovens e adultos ou Literacia na formação de professores. De toda a forma que, as sociedades contemporâneas são sociedades das literacias. A concepção de literacia é tratada como uma competência transversal associada aos mais diversos contextos da vida social, porque são múltiplos os contextos, bem como múltiplos são os espaços onde os processos de literacia podem ser desencadeados, sejam eles em espaços educativos formais, como a escola ou em espaços não formais.

\section{Literacia para as Mídias}

$\mathrm{Na}$ esteira das sociedades contemporâneas e em entremeio às suas facetas multidimensionais encontram-se as mídias, que, devido ao seu indubitável impacto e sua difusão por todo o mundo, configuram-se como um fato consumado nos processos de desenvolvimento dos sujeitos, bem como um elemento de cultura. Nesta reflexão, partimos de um conceito ampliado de mídia compreendida aqui "como todo o aparato simbólico e material que se dedica deliberadamente à produção de mercadorias de caráter cultural e simbólico" (SETTON, 2015, p.7) e que participa na formação cognitiva e da identidade dos indivíduos na atualidade. Assinalamos a centralidade das mídias na vida das pessoas enquanto lugares de produção e circulação de saberes, e que condicionam e influenciam, juntamente com a escola e outros agentes de socialização, os processos de formação do indivíduo. Não são raros os casos em que as crianças e jovens permanecem mais tempo em relação direta com as mídias do que na escola, e, de fato, os indivíduos se constituem cada vez mais e de forma intensa em consumidores e produtores midiáticos. Nesta perspectiva, não se pode negar a omnipresença e a importância que as mídias têm alcançado em nossa vida individual e coletiva. Não se pode ignorar, também, que a paisagem midiática nas últimas décadas tenha apresentado transformações extraordinárias e com impactos sensivelmente profundos na educação, na cultura, na política, 
na economia e, de maneira geral, no cotidiano de todas as pessoas.

Dito isso, é possível afirmar que as mídias representam, nas sociedades contemporâneas, não somente fontes de informação, mas mediadores pelos quais os sujeitos, em grande medida, vêm se relacionando, compreendendo e significando o que os cerca. Elas, mesmo não tendo o monopólio da informação, coexistem com outras instâncias formativas e compõem um rol de mediações através e com as quais damos inteligibilidade ao mundo. As mídias, muito presentes no processo de difusão de informações e hábitos, elaboração e apreensão de novas ideias, produção de sentidos, troca de conteúdos e mensagens, fomentam espaços de socialização, relacionamento, interação e exercem, ao mesmo tempo, um papel de interlocutores sociais e educativos. Pensados nesta perspectiva, mais do que apoiar cegamente ou condenar seu poder, é preciso reconhecer que elas se constituem como espaços de aprendizagem não-formal na medida em que são agentes de produção de um número imensamente significativo de informações, valores, símbolos e significados que coparticipam junto aos indivíduos na organização de suas vidas e suas ideias, a formarem suas opiniões ou oferecendo ferramentas para compreender, se adaptar ou transformar o seu mundo.

Partindo do pressuposto de que os indivíduos estabelecem uma relação quase que ubíqua com as tecnologias da informação e comunicação, e, por extensão, com as diversas mídias, as adicionando de modo quantitativo e qualitativo ao seu universo pessoal e social, fazse imprescindível pensar que tipo de relação estabelecemos com elas, bem como pensarmos na formação do indivíduo que com elas convive hodiernamente. Cresce, cada vez mais, na sociedade da informação, a necessidade e urgência de estabelecermos processos pedagógicos (formais ou informais) que capacitem os sujeitos a fim de que sejam capazes de, aproveitando os recursos e as oportunidades que os meios e as redes de comunicação oferecem, efetivamente, estabelecerem uma relação ativa, autônoma, crítica e responsável para e com eles.

De fato, como preconizava, ainda em 1982, a Declaração de Grünwald ${ }^{5}$ sobre Literacia para os Medias ${ }^{6}$, é essencial desenvolver conhecimentos, aptidões e atitudes que favoreçam o

\footnotetext{
${ }^{5}$ Declaração assumida por educadores, comunicadores e investigadores oriundos de 19 países e participantes no simpósio internacional reunido em Grünwald, na República Federal da Alemanha, de 18 a 22 de janeiro de 1982, a convite da UNESCO. Disponível em: http://www.literaciamediatica.pt.

${ }^{6}$ No contexto e no cenário lusófono português utiliza-se o termo "os Media" para designar este conjunto de plataformas de produção, distribuição e consumo de conteúdos por meios tecnológicos, ou os Meios de Comunicação. Portanto,
}

Periódico Horizontes - USF - Itatiba, SP - Brasil - e020050 
crescimento de uma consciência crítica e, consequentemente, de uma maior competência entre os consumidores, produtores e utilizadores das mídias. Num cenário,

[...] marcado pela multiplicidade de suportes, de formatos, de conteúdos, de mensagens, marcado pela conexão mídia-tecnologia, marcado pela pluralidade de discursos, pela vertigem da atualidade, pela voragem da mudança e da descoberta de novos acontecimentos, os media organizam e estruturam a nossa ligação ao mundo (LOPES, 2011, p.20).

Recebendo designações diversas ${ }^{7}$, por vezes associadas a diferentes abordagens, mas com uma preocupação comum, a Literacia para as Mídias, preconiza a necessidade de preparar ou criar condições para que os sujeitos saibam (con)viver com e num mundo rodeado pelas mídias e lidem de forma crítica e criteriosa com a panóplia de meios, informações, saberes e de conteúdos midiáticos que estão ao seu alcance.

Em termos históricos é possível perceber algumas orientações nas quais se assentaram os processos de Literacia para as Mídias. Segundo Pinto (2011), predominou até a década de 1960 a orientação que focava esforços na "proteção" visto os possíveis efeitos nocivos das mídias. Esta concepção caracterizava a criança como indefesa, desprotegida e fortemente influenciável, precisando que fossem construídas barreiras que as protegessem dos conteúdos midiáticos e seus possíveis efeitos negativos. Tal entendimento assentava suas premissas no princípio dos efeitos diretos das mídias. Apostava-se fortemente na regulamentação, especialmente por parte do Estado. Esta perspectiva ainda permanece latente nos dias atuais, especialmente quando se trata das preocupações em torno da internet. Outra orientação que se pode notar a partir do início do século XX, é a que Pinto (2011) denomina "modernizadora ou tecnológica", centrada no acesso e no uso das novas tecnologias. Acreditava-se que, em

quando este cenário for referido no transcurso deste artigo será usado o termo português de Portugal, bem como as citações respeitarão a língua em que foram escritas.

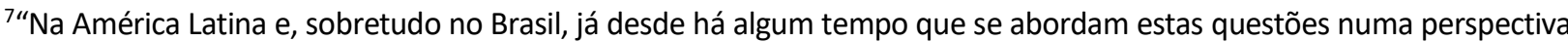
mais abrangente da Pedagogia da Comunicação, a qual inclui assiduamente uma perspectiva próxima do papel social, cultural e pedagógico dos próprios canais e dos meios, ou seja, mais próxima também do sentido mais estrito da Pedagogia dos Media, ou 'da Mídia'” (REIA-BAPTISTA, 2008, p.72-73). Para Pinto (2011) não há uma designação única e é frequente surgirem como análogos ao conceito de Literacia ou Educação para os media outros como Literacia Mediática, Educação para a comunicação ou Literacia Digital. Em países da América Latina, como é o caso do Brasil, são ainda frequentes as designações Alfabetização Midiática ou Educomunicação. Mais do que as nomenclaturas, o importante é o que designam, o que anunciam e o que valorizam é o que pode nos orientar. 
decorrência da modernização nas instituições educativas e com a introdução de inovações nos processos de ensino aprendizagem, viesse, como uma decorrência inevitável, quase que de forma natural, uma educação para as mídias. No entanto, essa orientação modernizadora está assentada numa perspectiva instrumentalista das tecnologias da informação e comunicação e reduzida ao seu fator técnico.

Distanciando-se das concepções protetoras e modernizadoras, claramente centradas nas mídias, Pinto (2011) acrescenta uma outra, a qual designa "capacitadora", na qual a ênfase desloca-se do "mediocentrismo" para o "sociocentrismo", "em que os próprios media, nas suas especificidades, tal como nos seus usos e formas de apropriação, são analisados como construções sociais" (2011, p.29). Esta concepção se orienta pelo

princípio da capacitação e autonomia progressivas dos sujeitos. Ou seja, considera-se que as crianças podem desenvolver, em relação aos media, atitudes e práticas activas e críticas, mas, para isso, precisam de apoio, de incentivo, de orientação, de mediação. Esta concepção considera que os sujeitos não são natural e espontaneamente críticos, precisam desenvolver essa capacidade, sendo esse o objectivo da Literacia para os Media. A preocupação inerente a esta orientação é também a de desenvolver e promover as capacidades de expressão e de participação dos sujeitos (PINTO, 2011, p.29).

Esta perspectiva assenta-se na aquisição de literacias que promovam individual e coletivamente uma relação informada, crítica e responsável dos sujeitos para com as mídias.

\section{Aportes ao diálogo a partir do cenário no continente europeu e em Portugal}

Mesmo não havendo consenso acerca do conceito de Literacia para as Mídias ou uma terminologia que designa tal concepção, cabe, contudo, apontar que o campo que procura conjugar o universo da educação e da comunicação é tangenciado por perspectivas diferenciadas, tão complexas como complexo é o leque dos desafios que, não só crianças e jovens, mas o conjunto geral dos cidadãos enfrenta nas sociedades do conhecimento e da informação. É possível perceber, no entanto, em documentos, iniciativas e programas pedagógicos, em maior ou menor grau, o que se pretende promover e significar com a perspectiva do uso esclarecido, da compreensão crítica e da atitude criativa frente a informação 
e às mídias tendo em vista a ostensiva presença destas em nosso cotidiano.

No âmbito do continente europeu, diversos documentos estabelecem diretrizes e orientações que demonstram o quanto o papel das mídias e da comunicação social no processo de desenvolvimento e formação do sujeito não deve ser subestimado ou mesmo ignorado, mas compreendido. A Comissão Europeia sobre Literacia Mediatica no Ambiente Digital preconiza a Literacia para as Mídias como "a capacidade de aceder aos media, de compreender e avaliar de modo crítico os diferentes aspectos dos media e dos seus conteúdos e de criar comunicações em diversos contextos" (EUROPA, 2009, n.p.). Nesta perspectiva, no documento afirma-se que esta é uma condição sinequa non para a inclusão socioeconômica e para o desenvolvimento de uma cidadania ativa, evitando, ou ao menos diminuindo os riscos, de exclusão da vida comunitária e contribuindo para reforçar valores como a diversidade, a tolerância, a transparência, a equidade e o diálogo. Neste sentido, apregoa-se a Literacia para as Mídias como uma competência crucial para a vida, tendo em vista que amplia as habilidades do sujeito em direção ao pensamento crítico, à capacidade de reflexão, impulsionando-o a uma alargada participação numa sociedade digital e do conhecimento.

Em 2010, uma diretiva do Parlamento Europeu sobre literacia conclui que "a literacia para os media visa às competências, aos conhecimentos e à compreensão que permitem aos consumidores utilizarem os meios de comunicação social de forma eficaz e segura" (EUROPA, 2010, n.p.). Desta maneira, a literacia é concebida como algo que engloba as múltiplas competências para compreender, avaliar e utilizar com espírito crítico as diversas formas de mídias e suas mensagens que nos chegam através de diferentes formas de comunicação (programas, filmes, imagens, textos, sons e sítios web etc.; abarcando desde os tradicionais, os novos e a convergência de ambos). Segundo consta no documento, os sujeitos educados para as mídias tendem a ser capazes de fazer escolhas informadas, compreender a natureza dos conteúdos e serviços e "tirar partido" de toda a gama de oportunidades oferecidas pelas novas tecnologias das comunicações. Aponta-se, portanto, para a necessidade de uma atitude crítica e de discernimento em relação às mídias e para a capacidade do cidadão tomar suas próprias decisões de forma autônoma, ativa e consciente, com base nas informações disponíveis.

Em Portugal, o Conselho Nacional de Educação, em uma recomendação sobre Educação para a Literacia Midiática de 2010, destaca que o mais importante a ser debatido hoje não são 
as mídias em si (naturalmente o que não exclui o debate sobre sua dimensão técnica), mas o seu uso informado, crítico e responsável. Neste sentido, aponta a urgência de três tipos de aprendizagem que podem possibilitar e potencializar a interatividade e formas de aprender mais ativas, mais participativas, individualizadas e com mais sentido, capazes de instituir novas configurações de participação social e política. Conforme o documento, uma Literacia para as Mídias pressupõe

o acesso à informação e à comunicação - o saber procurar, guardar, arrumar, partilhar, citar, tratar e avaliar criticamente a informação pertinente, atentando também à credibilidade das fontes; a compreensão crítica dos media e da mensagem mediática - quem produz, o quê, porquê, para quê, por que meios; o uso criativo e responsável dos media para expressar e comunicar ideias e para deles fazer um uso eficaz de participação cívica (PORTUGAL, 2011, p.5).

Em Portugal, um movimento acadêmico e político se intensifica em direção à adoção de práticas (inclusive escolares) voltadas à Literacia para as Mídias. É possível encontrar projetos interessantes, diversificados e reveladores, mesmo que, segundo Pinto (2011, p.149), ainda insuficientes e, em geral, fragmentados. Neste cenário destaca-se o Manifesto de Braga em que se afirma ser de indiscutível importância o fomento de processos educativos voltados para o uso esclarecido das mídias, os quais fazem parte de uma dimensão autônoma da educação para a cidadania. O manifesto propõe que as mídias sejam tomadas não apenas como recursos ou apoio, mas também como objetos de estudo e oportunidades de participação. Neste sentido, deveria haver um esforço conjunto entre os mais diversos atores sociais, estejam eles presentes na escola, na família, na sociedade em geral e nas próprias mídias, no sentido de "requerer uma literacia para os media que diga respeito a todas as idades, em todos os contextos, e articula-se com a necessidade de aquisição de outras literacias que o mundo globalizado e complexo cada vez mais exige" (CONGRESSO, 2011, p.1).

No estudo realizado pelo Centro de Estudos em Comunicação e Sociedade da Universidade do Minho, de Braga, Portugal, realizado com o apoio da Entidade Reguladora para a Comunicação Social (ERC), publicado em 2011, intitulado Educação para os Media em Portugal: experiências, actores e contextos ${ }^{8}$, são apontados dois programas que procuram conjugar

\footnotetext{
${ }^{8}$ A publicação completa está disponível em http://www.erc.pt/pt/estudos-e-publicacoes/literacia-para-os-media
}

Periódico Horizontes - USF - Itatiba, SP - Brasil - e020050 
diversas vertentes e um conjunto de possibilidades de exploração de temas e que foram integrados a planos curriculares com adaptações específicas em diversos países. Tais propostas nos ajudam a compreender o projeto reflexivo da Literacia para as Mídias, considerando as complexas dimensões do fenômeno midiático e a preocupação com o desenvolvimento de uma vertente didática com o objetivo de munir ações educativas e iniciativas voltadas para a desconstrução dos discursos midiáticos e a promoção de uma cidadania ativa, informada e consciente. Ambas valorizam uma abordagem didático-pedagógica das mídias levando em conta um possível desenvolvimento, inclusive curricular, de Literacia para as Mídias.

Um dos quadros, desenvolvido pelo ResourceGuide for Media Literacy do Canadá, publicado em 1989, destaca alguns conceitos-chave para a promoção de uma Literacia para as Mídias, concebida como o processo de compreender e usar as mídias no sentido de ajudar os estudantes a desenvolver um entendimento crítico e informado acerca da natureza dos meios, das técnicas que usam e o impacto de seus programas:

Quadro 1 - Conceitos-chave da Educação para as Mídias

\begin{tabular}{|l|l|}
\hline \multicolumn{1}{|c|}{ Conceitos-chave } & \multicolumn{1}{c|}{ Considerações/Questões } \\
\hline $\begin{array}{l}\text { 1. Todos os media são } \\
\text { uma construção }\end{array}$ & $\begin{array}{l}\text { Os meios de comunicação não apresentam simples reflexões } \\
\text { acerca da realidade. Em vez disso, eles difundem construções } \\
\text { cuidadosamente trabalhadas que reflectem muitas decisões e } \\
\text { apresentam-nos versões da realidade. A Literacia para os media } \\
\text { trabalha no sentido de desconstruir essas construções, } \\
\text { desmontá-las para mostrar como são feitas. Questões: Como é } \\
\text { que esta mensagem é construída? Até que ponto representa } \\
\text { bem a realidade? }\end{array}$ \\
\hline $\begin{array}{l}\text { 2. Os media } \\
\text { constroem a realidade }\end{array}$ & $\begin{array}{l}\text { Os media são responsáveis pela maioria das observações e } \\
\text { experiências a partir das quais construímos nossa compreensão } \\
\text { pessoal do mundo, e de como ele funciona. Grande parte da } \\
\text { nossa visão da realidade baseia-se nas mensagens dos media, } \\
\text { que são construídas. Em grande medida, os media dão-nos o } \\
\text { sentido da realidade. }\end{array}$ \\
\hline $\begin{array}{l}\text { 3. A audiência } \\
\text { interpreta o } \\
\text { significado nos media }\end{array}$ & $\begin{array}{l}\text { Os media proporcionam-nos grande parte do material sobre o } \\
\text { qual construímos a nossa imagem da realidade, e todos nós } \\
\text { "negociamos" o significado de acordo com factores individuais: } \\
\text { necessidades e ansiedades pessoais; os prazeres ou problemas } \\
\text { do dia-a-dia; as atitudes raciais e sexuais; o background familiar } \\
\text { e cultural etc. }\end{array}$ \\
\hline
\end{tabular}

Periódico Horizontes - USF - Itatiba, SP - Brasil - e020050 


\begin{tabular}{|c|c|}
\hline $\begin{array}{l}\text { 4. Os media têm } \\
\text { interesses comerciais }\end{array}$ & $\begin{array}{l}\text { A Literacia para os Media visa desenvolver a consciência acerca } \\
\text { de como os media são influenciados por aspectos comerciais e } \\
\text { como estes afectam a técnica, o conteúdo e a distribuição. A } \\
\text { maior parte da produção dos media é um negócio que visa lucro. } \\
\text { As questões de propriedade e controle são fundamentais: um } \\
\text { número relativamente pequeno de grupos a controlar o que } \\
\text { vemos, lemos e ouvimos nos media. Questões: quem criou este } \\
\text { produto/mensagem e porquê? Quem lucra se a mensagem for } \\
\text { bem recebida? Quem pode ser prejudicado? }\end{array}$ \\
\hline $\begin{array}{l}\text { 5. Os media contêm } \\
\text { mensagens de teor } \\
\text { ideológico e de } \\
\text { valores }\end{array}$ & $\begin{array}{l}\text { De certo modo, todos os produtos mediáticos fazem publicidade } \\
\text { na medida em que proclamam valores e estilos de vida. Explícita } \\
\text { ou implicitamente, os media transmitem mensagens ideológicas } \\
\text { sobre questões como a qualidade de vida, o consumismo, o } \\
\text { papel das mulheres, a aceitação da autoridade e o patriotismo. } \\
\text { Questões: Que estilos de vida, valores e pontos de vista estão } \\
\text { representados ou estão omissos nesta mensagem? }\end{array}$ \\
\hline $\begin{array}{l}\text { 6. Os media têm } \\
\text { implicações sociais e } \\
\text { políticas }\end{array}$ & $\begin{array}{l}\text { Os media têm grande influência na política e na mudança social. } \\
\text { A televisão pode influenciar fortemente a eleição de um líder } \\
\text { nacional, com base na imagem. Os meios de comunicação } \\
\text { envolvem-nos em preocupações como as questões dos direitos } \\
\text { civis, a fome e a epidemia da Sida. Eles fornecem-nos um sentido } \\
\text { íntimo das questões nacionais e das preocupações globais, para } \\
\text { que nos tornemos cidadãos da "Aldeia Global" de Marshall } \\
\text { McLuhan. }\end{array}$ \\
\hline $\begin{array}{l}\text { 7. A forma e o } \\
\text { conteúdo estão } \\
\text { intimamente } \\
\text { relacionados }\end{array}$ & $\begin{array}{l}\text { Como Marshall McLuhan observou, cada meio tem a sua própria } \\
\text { gramática e codifica a realidade de modo particular. Diferentes } \\
\text { meios de comunicação irão relatar o mesmo evento, mas criar } \\
\text { diferentes impressões e mensagens. }\end{array}$ \\
\hline $\begin{array}{l}\text { 8. Cada meio tem uma } \\
\text { forma estética única }\end{array}$ & $\begin{array}{l}\text { Assim como percebemos os ritmos agradáveis de determinados } \\
\text { elementos de poesia ou de prosa, devemos também ser capazes } \\
\text { de desfrutar as formas agradáveis e os diferentes efeitos dos } \\
\text { meios de comunicação. }\end{array}$ \\
\hline
\end{tabular}

Fonte: (PINTO, 2011, p.34-35)

O outro quadro sugerido por Pinto (2011, p.31-32) foi proposto pelo British FilmInstitute da Inglaterra, num documento intitulado 'Curriculum Statements' publicado em 1989 e organizado com base na compreensão conceptual e não em termos de objeto de estudo ou de capacidades e competências. Nele são apontadas algumas áreas-chave (não muito distantes da proposta canadense) da Literacia para as Mídias, que se traduzem a partir de questões que são centrais. A proposta entende que um processo voltado para o desenvolvimento de Literacia para as Mídias deve levar em conta a compreensão das instituições (quem comunica e por quê?), das 
categorias envolvidas (de que tipo de 'texto' se trata?), da tecnologia empregada (como é produzido?), da linguagem utilizada (como sabemos o que significa?), das representações presentes (como é retratado um determinado assunto?) e das audiências a serem alcançadas (quem recebe o texto e que tipo de significado lhe atribui?).

\section{Palavras propositivas: literacia para as Mídias na escola}

A Literacia para as Mídias pode e deve envolver diversos públicos, atores e contextos, a fim de se desenvolver em uma diversidade de ambientes sejam eles formais ou informais ${ }^{9}$. A escola ainda é um lócus privilegiado e, comumente, o mais apontado para este movimento formativo ${ }^{10}$. No entanto, a utilização dos recursos midiáticos como auxiliares didáticospedagógicos é, em geral, a forma de abordagem mais presente no contexto escolar, o que tem reduzido a ação escolar em termos de literacia. Lopes (2011) destaca que, em um mundo marcado pela presença ostensiva das mídias, a Literacia para as Mídias "consiste, em primeiro lugar, na tomada de consciência deste mundo mediático, da obrigação vital, individual e colectiva de aprender os seus pressupostos, como se aprende a ler e a escrever para não se ser analfabeto" (LOPES, 2011, p.22). Neste âmbito,

[...] os grandes objectivos da Literacia para os Media são, por um lado, 'ensinar a pensar a cultura mediática e a reflectir sobre a realidade' e, por outro, preparar para a autoria competente e responsável de conteúdos. Isto quer dizer que, por um lado, a Literacia para os Media deve assentar na desconstrução crítica e reflexiva - do discurso dos media, o que implica noções básicas dos seus códigos e da sua gramática narrativa, e, por outro, na capacitação dos sujeitos para a produção (construção) de mensagens mediáticas (LOPES, 2011, p.23).

Tendo por base tais perspectivas foi aprovado em 2014, no âmbito do Ministério da Educação e Ciência português, um Referencial de Educação para os Media para a Educação Préescolar, o Ensino Básico e o Ensino Secundário. O documento foi produzido no sentido de propor

\footnotetext{
${ }^{9}$ A Literacia para as Mídias pode e deve ser promovida em diversos contextos, para além do ambiente escolar: ambientes informais, como associações de jovens ou comunitárias, bibliotecários, animadores socioculturais, grupos e associação de pais, empresas de mídia, públicas, privadas ou comunitárias, serviços de saúde, meios universitários e de investigação, igrejas ou grupos religiosas etc.

${ }^{10} \mathrm{Em}$ alguns países - por exemplo: Suécia, Irlanda, Reino Unido - a Literacia para as Mídias já faz parte do currículo escolar.
}

Periódico Horizontes - USF - Itatiba, SP - Brasil - e020050 
um quadro de referência para o trabalho pedagógico em torno de questões desta natureza no país e afirma que a Literacia para as Mídias não se reduz, nem pode ser confundida com o uso das mídias na educação, mas envolve a aquisição de capacidades de reflexão e espírito crítico que habilitem o sujeito a comunicar através das mídias e com as próprias mídias, rejeitando, assim, a reprodução gratuita de modos de vida, comportamentos e ideias, e contribuindo para a formação de sujeitos capazes de "ler criticamente" as mídias. Não se trata, pois, de direcionar esforços para a mera utilização das tecnologias, nem mesmo a introdução de uma lista de conteúdos para simplesmente serem ministrados aos alunos ou serem abordados de forma isolada.

Dessa forma, uma proposta de Literacia para as Mídias a ser adotada na escola deve ensinar a pensar a cultura midiática e a refletir sobre a realidade preparando de forma concomitante a autoria responsável e consciente de conteúdos. Ou seja, deve assentar-se, por um lado "na desconstrução - crítica e reflexiva - do discurso dos media, o que implica noções básicas dos seus códigos e da sua gramática narrativa, e, por outro, na capacitação dos sujeitos para a produção (construção) de mensagens mediáticas" (LOPES, 2011, p.23). É por este viés que Tornero (2007, p.158) afirma que a Literacia para as Mídias "alcança o seu grau máximo de realização quando o estudante tem a oportunidade de criar e desenvolver - através dos e com os media - as suas próprias mensagens", de forma autônoma, informada e criativa.

\section{Considerações finais}

Os processos comunicativos e as tecnologias, que em grande parte os mediam, moldaram as sociedades humanas, ao mesmo tempo em que, por elas, foram construídos, apropriados e dotados de significados. Particularmente, com o advento das mídias de massa, desde as clássicas às nominadas novas mídias, criou-se um ambiente capaz de propiciar diferentes formas e níveis de comunicação e informação. Aquilo que por elas circulam não somente refletem a realidade social, mas são, sobretudo e, necessariamente, interpretações desta realidade.

As mídias não funcionam à revelia da sociedade. Isto significa dizer que são uma construção social, deliberadamente constroem realidades e as interpretam e, nesta perspectiva, suas ações têm implicações sociais e políticas. 
Para compreender este ecossistema comunicativo e midiático é preciso perceber o que os sujeitos fazem quando envoltos nele, que lugares eles ocupam e que repercussões suscitam. Importa, para isso, alargar as capacidades do sujeito para estabelecer uma relação crítica frente às mídias a fim de que ele seja capaz de não apenas avaliá-las criticamente assim como a informação, mas fazer uso consciente e responsável delas. Esta é a proposta da Literacia para as Mídias que preconiza o desenvolvimento de competências, conhecimentos, habilidades e compreensões que permitam aos sujeitos o uso crítico da informação e das mídias de maneira a melhor compreender a natureza da produção, os impactos dos conteúdos e poder desenvolver capacidades para uma produção de discursos e conteúdos de forma criativa e autônoma. A Literacia para as Mídias é entendida como um processo transversal que se preocupa muito menos com a reflexão acerca da utilização das tecnologias, mas com processos pedagógicos que capacitem os sujeitos a fim de que saibam conviver melhor informados e esclarecidos neste ecossistema midiático e informacional.

Nesta perspectiva advogamos que, mesmo sendo esta proposta potente a ser desenvolvida através de projetos e programas em espaços de educação informal, as escolas e os professores continuam a ser um lócus imprescindível para a realização de experiências pedagogias voltadas às dimensões da Literacia para as Mídias, seja na forma de disciplinas específicas, na inclusão destes temas em diversas matérias e nos diferentes níveis de ensino ou em projetos pedagógicos específicos.

Por fim compreendemos que no atual ambiente midiático e no atual contexto sóciopolítico, a Literacia para as Mídias, o que inclui a literacia digital, pode ser um meio para um exercício mais informado da cidadania, o que pode contribuir para uma esfera pública mais crítica e mais sofisticada permitindo capacitar os cidadãos para uma participação mais ativa e responsável na sociedade.

\section{Referências}

BENAVENTE, A. Literacia e cidadania. In: SALGADO, L. Literacia e aprendizagem da leitura e da escrita. Lisboa: Ministério da Educação, p.21-23, 1995.

CONGRESSO Nacional Literacia, Media e Cidadania. Literacia dos media: declaração de Braga. In: CONGRESSO NACIONAL LITERACIA, MEDIA E CIDADANIA, 2011, Braga. Anais [...]. Braga: 
Universidade do Minho / Centro de Estudos de Comunicação e Sociedade, 2011. 3 p. Disponível em: http://www.gmcs.pt/pt/declaracao-de-braga-sobre-literacia-para-os-media. Acesso em: 10 jun. 2017.

EUROPA. Comissão Europeia sobre Literacia Mediática no Ambiente Digital. Sobre literacia mediática no ambiente digital.2009. Disponível em: http://www.gmcs.pt/pt/recomendacao-dacomissao-europeia-sobre-literacia-mediatica-no-ambiente-digital. Acesso em: 18 maio 2017.

EUROPA. Parlamento Europeu. Oferta de serviços de comunicação social audiovisual.2010. Disponível em: http://www.gmcs.pt/pt/directiva-201013ue-directiva-servicos-de-comunicacaosocial-audiovisual. Acesso em: 10 maio 2017.

LOPES, P.C. Educação para os media nas sociedades multimediáticas. CIES e-WorkingPaper, n. 108, 2011. Disponível em: http://cies.iscte-iul.pt/destaques/documents/CIESWP108_Lopes.pdf. Acesso em: 10 jun. 2018.

PINTO, M. Informação, conhecimento e cidadania - a educação escolar como espaço de interrogação e de construção de sentido. Braga: Centro de Estudos de Comunicação e Sociedade, p.1-14, 2002. Disponível em: http://repositorium.sdum.uminho.pt/bitstream/1822/2758/1/mpinto_IntervGulb_2002.pdf. Acesso em: 20 nov. 2017.

PINTO, M. Educação para os media em Portugal: experiências, actores e contextos. Lisboa: ERC, 2011.

PORTUGAL. Conselho Nacional de Educação. Recomendação sobre educação para a literacia mediática.2011. Disponível em: http://www.gmcs.pt/ficheiros/pt/recomendacao-do-conselhonacional-de-educacao-sobre-educacao-para-a-literacia-mediatica.pdf. Acesso em: 20 maio 2017.

REIA-BAPTISTA, V. Conceitos e processos formativos de pedagogia e literacia dos media. Revista Portuguesa de Pedagogia, Coimbra,ano 42-2, p.65-77, 2008. Disponível em: https://core.ac.uk/download/pdf/61507013.pdf. Acesso em: 20 maio 2017.

SETTON, M. G. Mídia e educação. São Paulo: Contexto, 2015.

TORNERO, J. M. Comunicação e educação na sociedade da informação: novas linguagens e consciência cívica. Porto: Porto Editora, 2007.

Recebido em agosto 2019.

Aprovado em abril 2020. 